Infusionsther Transfusionsmed 1993;20(suppl 2):2

\title{
Impressum, Vol. 20, Supplement 2, 1993
}

Offizielles Organ

der Deutschen Gesellschaft für Transfusionsmedizin

und Immunhämatologie

Gründungsherausgeber

H. Reissigl, Innsbruck

Herausgeber

J. Eckart, Augsburg V. Kretschmer, Marburg K. Meßmer, München K. Peter, München W.

Stangel, Hannover K.-H. Usadel, Frankfurt

Schriftleiter

H. Forst, München

Assistent des Schriftleiters

B. Zwißler, München

Wissenschaftlicher Beirat

M. Adolph, Augsburg

F.W. Ahnefeld, Ulm

J. Askanazi, New York

C. Baldamus, Köln

H. Bardenheuer, München

J.-F. Baron, Paris

K.-H. Bäßler, Mainz

W. Behrendt, Aachen

H. Borberg, Köln

U. B. Bruckner, Ulm

W. Dick, Mainz

J. Eckart, Augsburg

R. Eckstein, Erlangen

A. Encke, Frankfurt

K. Falke, Berlin

U. Finsterer, München

H. Forst, München

L. Frey, München

Y. Fujita, Okayama

L. Gattinoni, Monza

M. Georgieff, Ulm

A. Grünert, Ulm

H. J. Gurland, München

P. Hanfland, Bonn

M. Heberer, Basel

J. P. Isbister, Sydney 


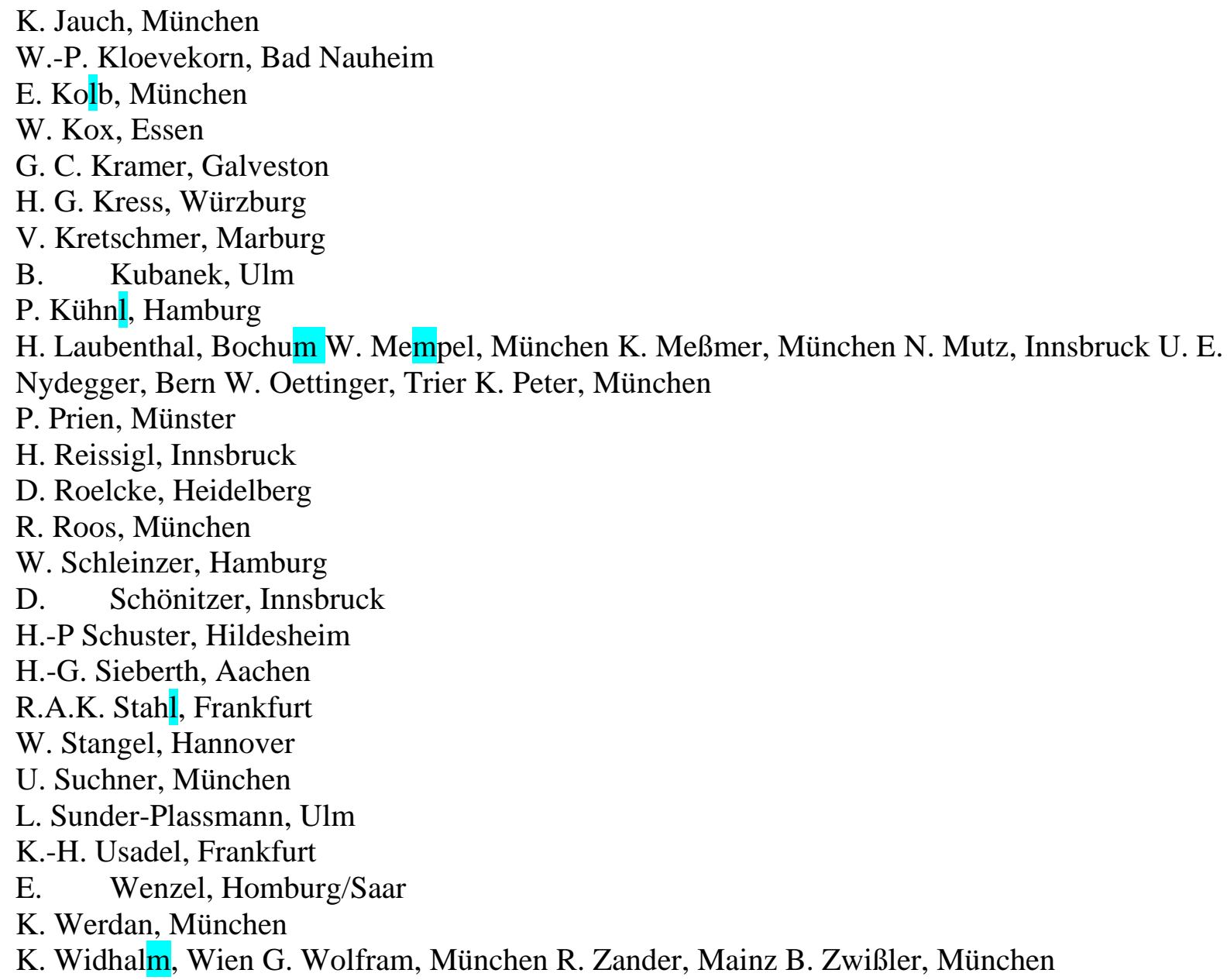

Supplement 2 zu Band 20, Juni 1993: ISBN 3-8055-5834-1. Ladenpreis dieses Sonderheftes DM 45,- inkl. MwSt. Abonnenten erhalten es unberechnet.

Die Zeitschrift erscheint zweimonatlich: pro Jahr erscheint 1 Band zu je 6 Heften. DGTIMitglieder erhalten die Zeitschrift im Rahmen ihrer Mitgliedschaft. Bezugspreis für Jahrgang 20, 1993: DM 159.- I öS 1113 - I SFr 124,-. 1 Einzelheft kostet DM 30,-/öS 210,-/SFr 23-, einschließlich MwSt., zuzüglich Postge-bühren. Der Abonnementpreis ist im voraus zahlbar. Das Abonnement der Zeitschrift läuft weiter, wenn es nicht spätestcns 4 Wochen vor Abschluß eines Bandes abbestellt wird. Abonnementbestellungen können bei jeder Buchhandlung oder direkt beim Verlag aufgegeben werden:

Bundesrepublik Deutschiand/Österreich: S. Karger GmbH, Lörracher Str. 16 a. W-7800 Freiburg (ab 1.7.93: D-79115 Freiburg), Tel. (0761) 452070, Fax (0761) 4520714, Postgiro München 61440-808.

Schweiz: S. Karger AG, Allschwilerstr. 10. Postfach, CH-4009 Basel, Telefon (061) 3061111, Telex $62652 \mathrm{CH}$, Telefax (061) 3061234. Anzeigen:

S. Karger Verlag für Medizin und Naturwissenschaften GmbH, Lörracher Str. 16 a, W-7800 Freiburg (ab 1.7.93: D-79115 Freiburg), Tel. (0761) 452070.

Gültig ist die Preisliste Nr. 10 vom 1. Januar 1993. 
Für den Inhalt außerhalb des redaktionellen Teiles (insbesondere Anzeigen.

Industríeinformationen, Pressezitate und Kongreßinformationen) übernehmen Schriftleitung,

Beirat und Verlag keine Gewähr.

Eine Markenbezeichnung kann warenzeichenrechtlich geschützt sein, auch wenn

bei ihrer Verwendung in diescr Zeitschrift das Zeichen ${ }^{\circledR}$ oder ein anderer Hinweis

auf etwa bestehende Schutzrechte fehlen sollte. Für Satzfehler, insbesondere bei

Dosierungsangaben, wird keine Gewähr übernommen.

Die Zeitschrift sowie alle in ihr enthaltenen einzelnen Beiträge und Abbildungen

sind urheberrechtlich geschützt. Jede Verwertung, die nicht ausdrücklich vom Urheberrechtsgesetz zugelassen ist, bedarf der vorherigen Zustimmung des Verlags. Das gilt insbesondere für Vervielfältigungen, Bearbeitungen, Übersetzungen, Mikroverfilmungen und die Einspeicherung und Verarbeitung in elektronischen Systemen. Fotokopien dürfen nur für den persönlichen Gebrauch als Einzclkopien hergestellt werden. Jede im Bereich eines gewerblichen Unlernehmens zulässig hergestellte oder benutzte Kopie dient gewerblichen Zwecken gem. § 54(2) UrhG und verpflichtet zur Gebührenzahlung an die Verwertungsgesellschaft WORT.

Abt. VG Wissenschaft, Goethestraße 49, W-8000 München 2.

(c) Copyright 1993 by S. Karger

Verlag für Medizin und Naturwissenschaften GmbH

Lörracher Str. 16 a. W-7800 Freiburg (ab 1.7.93: D-79115 Freiburg)

Verlagsleitung: Steven Karger

Presserechtlich verantwortlich: Georg Brunner

Redaktionsassistenz: Martina Zeller

Anzeigenverwaltung: Christiane Opitz

Satz und Druck: Walter Biering GmbH Grafischer Betrieb

Freisinger Landstraße 21 , W-8000 München 45

KARGER 